\title{
Role of three-dimensional transvaginal sonography compared with magnetic resonance imaging in diagnosis of Mullerian duct anomalies
}

\author{
Sahar Mahmoud Abd elsalam ${ }^{1 *}$, Naglaa Ezzat Abd elmegeed ${ }^{1}$, Ahmed Hesham Mohammed Said ${ }^{1}$ and \\ Mohamed Abd elghafar Sayed ${ }^{2}$
}

\begin{abstract}
Background: Mullerian duct anomalies are a heterogenous group of congenital anomalies due to abnormalities during the ductal development, fusion, or alteration of septal resorption. These lead to the occurrence of different uterine anomalies. The present study aimed to assess the value of three-dimensional transvaginal sonography (3DTVS) in comparison with pelvic MRI to diagnose uterine anomalies. We prospectively evaluated 30 female patients, from January 2016 to May 2017. Their ages ranged from 18 to 40 years. Cases were referred from obstetrics and gynecology clinic with suspected uterine anomalies by 2DUS or with HSG done for infertility workup. 3DTVS and MRI examination were done for all patients.

Results: The final diagnosis of patients by MRI according to The European Society of Human Reproduction and Embryology-European Society for Gynaecological Endoscopy consensus classification included 2/30 (6.7\%) patients classified as class U0, 4/30 (13.3\%) patients classified as class U1, 17/30 (56.7\%) cases classified as class U2, 2/30 (6.7\%) patients classified as class U3, 3/30 (10\%) patients classified as class U4, and 2/30 (6.7\%) patients were classified as class U5. There was a significant strong agreement between the diagnosis by 3D-transvaginal ultrasound and MRI $(P<0.01)$.

Conclusion: 3DTVS proved to be highly accurate in the diagnosis of uterine anomalies and showed strong agreement with MRI, as both can provide valuable information about both the internal details and the external contour of the uterus.
\end{abstract}

Keywords: 3DTVS, MRI, Mullerian duct, Uterine, Anomalies

\section{Background}

Mullerian duct anomalies are heterogenous spectrum of congenital anomalies that result from abnormalities during the ductal development, ductal fusion, or alteration of septal resorption. These abnormalities lead to the occurrence of different uterine anomalies [1].

\footnotetext{
*Correspondence: shahdsahar@yahoo.com; saharmahmoud575@gmail.com 'Radiology Department, Faculty of Medicine, Beni-Suef University, Beni Suef, Egypt

Full list of author information is available at the end of the article
}

Early detection and proper diagnosis of uterine anomalies are needed to distinguish operable from inoperable cases. Most of the patients present with infertility, repeated first-trimester abortion, fetal intrauterine growth restriction, and obstetric complications [1].

Several trials have been made for proper and accurate classification of Mullerian duct anomalies. The American Society for Reproductive Medicine (ASRM) classification is considered the most commonly used one (Fig. 1) [3]. The European Society of Human Reproduction and Embryology-European Society for Gynaecological 


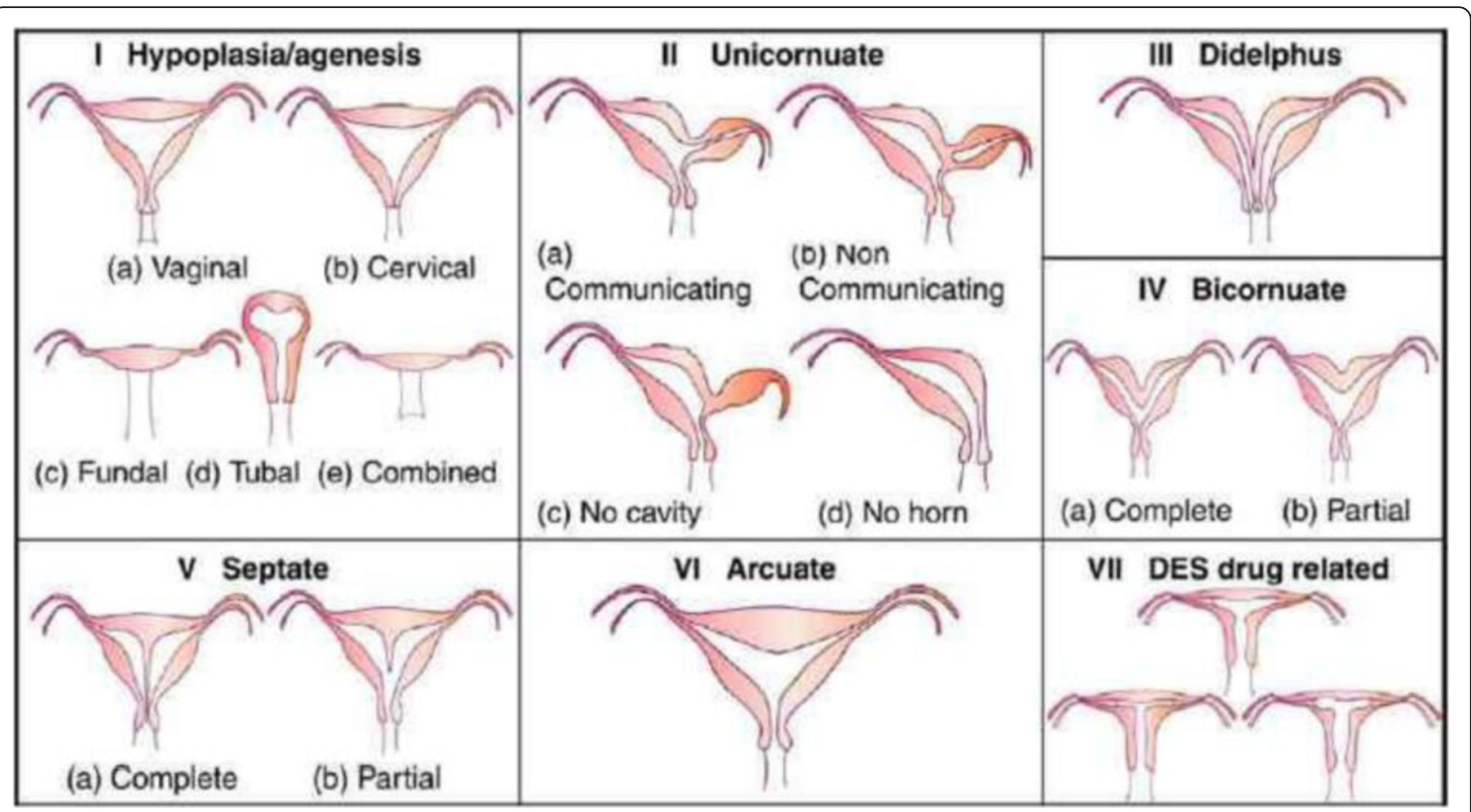

Fig. 1 Classification of congenital uterine anomalies as described by the American Fertility Society [2]

Endoscopy (ESHRE-ESGE) is used to limit the subjective diagnosis of the American classification. It helps in the differentiation of septate uterus from similar anomalies, regardless of the absolute morphological characteristics [4]. The arcuate uterus entity is not present in the ESHRE-ESGE classification. This classification includes uterine anomaly main classes and subclasses as well as cervical and vaginal anomalies as coexistent subclasses, as shown in Tables 1 and 2 [6, 7].

There are different imaging modalities that can be used for the diagnosis of uterine malformations. Hysterosalpingography (HSG) and hysteroscopy are considered good modalities to assess the uterine cavity. Laparotomy and laparoscopy are also used for providing information about the external contour and uterine cavity [7].

Pelvic magnetic resonance imaging (MRI) has also been proven to be excellent in the diagnosis of Mullerian duct anomalies due to high soft tissue resolution. MRI examination is more expensive and less available than other imaging modalities [8].

Three-dimensional ultrasound represents a valid alternative or adjunct to pelvic MRI. It is less expensive than MRI and being better tolerated by patients. Threedimensional transvaginal sonography (3DTVS) provides image quality like those provided by magnetic resonance imaging [9].

So, the aim of our study was to assess the value of 3DTVS in comparison with that of pelvic MRI to diagnose cases with uterine anomalies.

\section{Methods}

\section{Patients}

The study included 30 married female patients. They were referred to the Radiology Department from the obstetrics and gynecology clinic of a university hospital in the period from January 2016 to May 2017. The study was approved by the ethical committee of our institution. All participants signed informed consent prior to the examinations. Most of the cases were presented with infertility and some cases with repeated abortion.

They were initially suspected to have uterine anomalies by 2D US or with HSG done for infertility workup, and then 3DTVS and MRI examinations were done for all patients. Exclusion criteria included cases with general contraindications to MRI examination and cases with prior gynecological operations.

\section{Methods}

\section{DTVS}

- We used (GE Voluson S6) ultrasound machine, equipped with endocavitary 3D probe RAB2-6 5-9 MHz.

- The uterus was first examined by a two-dimensional ultrasound in a strict mid-sagittal view showing the uterus from the fundus to the cervix, with the 
Table 1 Ultrasound criteria for the classification of congenital uterine anomalies by ESHRE-ESGE [5]

\begin{tabular}{|c|c|}
\hline & Uterine cavity shape \\
\hline $\begin{array}{l}\text { Class U0: normal } \\
\text { uterus }\end{array}$ & $\begin{array}{l}\text { Straight, curved interostial } \\
\text { line or internal indentation } \\
<50 \% \text { myometrial thicknes }\end{array}$ \\
\hline $\begin{array}{l}\text { Class U1: } \\
\text { dysmorphic } \\
\text { uterus }\end{array}$ & Abnormal \\
\hline a. T-shaped & $\begin{array}{l}\text { Narrow cavity; thickened } \\
\text { lateral walls; correlation of } \\
\text { two-third uterine corpus } \\
\text { and one-third cervix }\end{array}$ \\
\hline b. Infantilis & $\begin{array}{l}\text { Narrow cavity without wall } \\
\text { thickening; correlation of } \\
\text { one-third uterine body and } \\
\text { two-third cervix }\end{array}$ \\
\hline c. Others & $\begin{array}{l}\text { Internal indentation }<50 \% \\
\text { myometrial thickness }\end{array}$ \\
\hline $\begin{array}{l}\text { Class U2: septate } \\
\text { uterus }\end{array}$ & $\begin{array}{l}\text { Internal indentation }>50 \% \\
\text { myometrial thickness }\end{array}$ \\
\hline a. Partial & $\begin{array}{l}\text { a. Division above of the } \\
\text { internal cervical os }\end{array}$ \\
\hline b. Complete & $\begin{array}{l}\text { b. Division up to the } \\
\text { internal cervical os }\end{array}$ \\
\hline
\end{tabular}

Class U3:

bicorporeal uterus

$\begin{array}{ll}\text { a. Partial } & \begin{array}{l}\text { Division above of the } \\ \text { internal cervical os }\end{array} \\ \text { b. Complete } & \begin{array}{l}\text { Division up to the internal } \\ \text { cervical os }\end{array} \\ \text { c. Bicorporeal } & \begin{array}{l}\text { Midline fundal indentation } \\ \text { (myometrial thickness at } \\ \text { the central point of the } \\ \text { external cleft) }>150 \% \\ \text { uterine wall thickness } \\ \text { (average myometrial } \\ \text { thickness }\end{array} \\ & \text { Unilateral formed }\end{array}$

uterus

a. With a
rudimentary
(functional)
cavity
b. Without
rudimentary
(functional)
cavity

Class U5: aplastic uterus

a. With $\quad$ Cavity remnant/s present
rudimentary
(functional)
cavity
b. Without Cavity remnants absent
rudimentary
(functional)
cavity
Class U6:
unclassified

Cavity remnant/s present

Full uterine aplasia or uterine remnants present

Infrequent anomalies, combined anomalies subtle changes, or

Table 2 ESHRE -ESGE main classes, subclasses, and coexistent cervical/vaginal subclasses [6]

\begin{tabular}{|c|c|c|c|}
\hline & \multicolumn{2}{|l|}{ Uterine anomaly } & \multirow{2}{*}{$\begin{array}{l}\text { Cervical/vaginal } \\
\text { anomaly } \\
\text { Coexistent subclass }\end{array}$} \\
\hline & Main class & Main subclass & \\
\hline \multirow{2}{*}{$\begin{array}{l}\text { Class } \\
0\end{array}$} & \multirow{2}{*}{\multicolumn{2}{|c|}{ Normal uterus }} & Cervix \\
\hline & & & Co normal \\
\hline \multirow{2}{*}{ Class } & \multirow{2}{*}{$\begin{array}{l}\text { Dysmorphic } \\
\text { uterus }\end{array}$} & a. T-shaped & C1 septate \\
\hline & & b. Infantile & C2 double "normal" \\
\hline \multirow[t]{2}{*}{$\begin{array}{l}\text { Class } \\
\|\end{array}$} & \multirow[t]{2}{*}{ Septate uterus } & a. Partial & $\begin{array}{l}\text { C3 unilateral cervix/ } \\
\text { dysplasia }\end{array}$ \\
\hline & & b. Complete & C4 aplasia/dysplasia \\
\hline \multirow{2}{*}{$\begin{array}{l}\text { Class } \\
\text { III }\end{array}$} & \multirow{2}{*}{$\begin{array}{l}\text { Dysfused } \\
\text { uterus } \\
\text { "including } \\
\text { septate" }\end{array}$} & a. Partial & \\
\hline & & b. Complete & Vagina \\
\hline \multirow{3}{*}{$\begin{array}{l}\text { Class } \\
\text { IV }\end{array}$} & \multirow{3}{*}{$\begin{array}{l}\text { Unilaterally } \\
\text { formed uterus }\end{array}$} & a. Rudimentary horn & V0 normal vagina \\
\hline & & $\begin{array}{l}\text { with cavity } \\
\text { (communicating or not) }\end{array}$ & $\begin{array}{l}\text { V1 longitudinal non- } \\
\text { obstructing vaginal } \\
\text { septum }\end{array}$ \\
\hline & & $\begin{array}{l}\text { b. Rudimentary horn } \\
\text { without cavity (no horn) }\end{array}$ & $\begin{array}{l}\text { V2 longitudinal } \\
\text { obstructing vaginal } \\
\text { septum }\end{array}$ \\
\hline \multirow[t]{2}{*}{$\begin{array}{l}\text { Class } \\
\mathrm{V}\end{array}$} & \multirow[t]{2}{*}{$\begin{array}{l}\text { Aplastic } \\
\text { dysplasia }\end{array}$} & $\begin{array}{l}\text { a. Rudimentary horn } \\
\text { with horn (bi-or } \\
\text { unilateral) }\end{array}$ & $\begin{array}{l}\text { V3 transverse vaginal } \\
\text { septum/imperforate } \\
\text { hymen }\end{array}$ \\
\hline & & $\begin{array}{l}\text { b. Rudimentary horn } \\
\text { with cavity }\end{array}$ & V4 vaginal aplasia \\
\hline $\begin{array}{l}\text { Class } \\
\mathrm{VI}\end{array}$ & \multicolumn{3}{|c|}{ Unclassified malformations } \\
\hline
\end{tabular}

endometrial line in a horizontal plane and perpendicular to the ultrasound beam.

- In any uterus with a large transverse diameter, another acquisition was made from a transverse section, where we used a $90^{\circ}$ sweep angle to obtain a multiplanar view of the uterus.

- The volume data were observed in three orthogonal planes and processed to do the needed reconstructions.

- The time of examination required for the diagnosis of uterine anomalies using a three-dimensional US, varied from $4 \mathrm{~min}$ to maybe up to $15 \mathrm{~min}$ in some complex cases.

\section{MRI imaging}

MRI was done by Siemens Magnetom Aera $1.5 \mathrm{~T}$ using senes body coil 18. Before the examination, all patients were instructed to have a full bladder.

Preliminary scout localizers in axial, coronal, and sagittal planes were done. Routine conventional MR study including axial T1 and T2, sagittal T2, and coronal T2 was done for all patients. Sequences were oriented according to the axis of the uterus. Coronal T2-weighted FSE was 
A

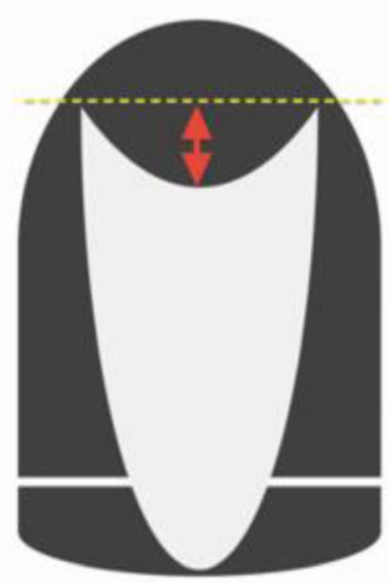

Internal identation
B

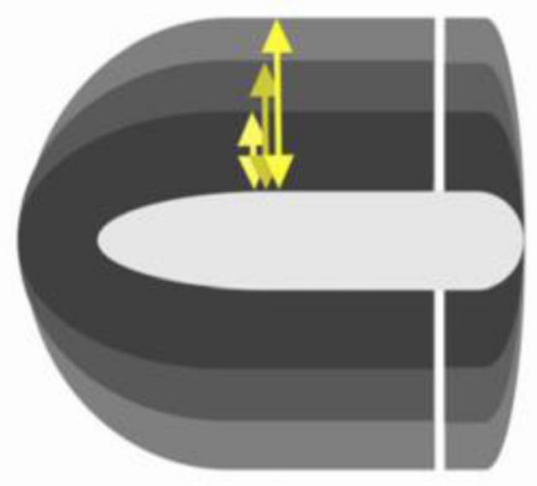

Uterine wall thickness
C

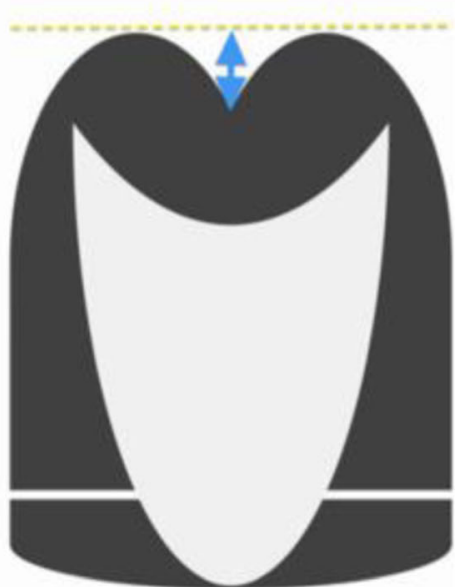

External cleft

Fig. 2 How to measure internal indentation and external cleft in the midcoronal plane (a and $\mathbf{c}$ ) and uterine wall thickness at the mid-sagittal plane (b) [10]

oriented parallel to the major uterine axis. The examination time took about $15 \mathrm{~min}$.

\section{Evaluation of findings}

The uterine morphology was interpreted in the coronal plane of the uterus with the interstitial portion of both Fallopian tubes as points of reference. We measured the internal indentation in the midcoronal plane, and according to its length, we classified cases into different classes. The external cleft also was measured in the midcoronal plane. The wall thickness was evaluated in the mid-sagittal plane (Fig. 2). The

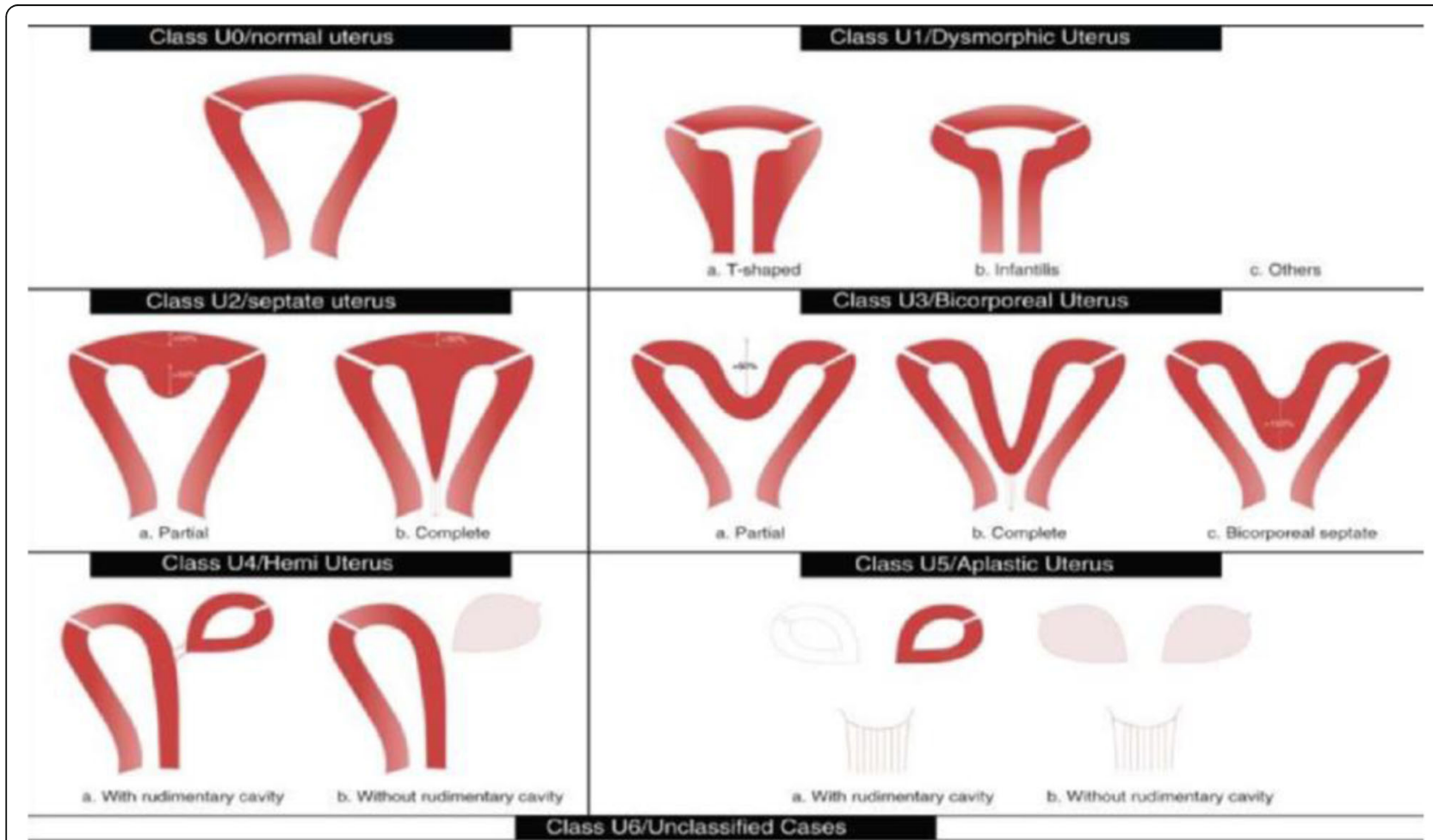

Fig. 3 Classification of congenital uterine anomalies as described by the European Society of Human Reproduction and Embryology and the European Society for Gynaecological Endoscopy ((ESHRE-ESGE) [6] 

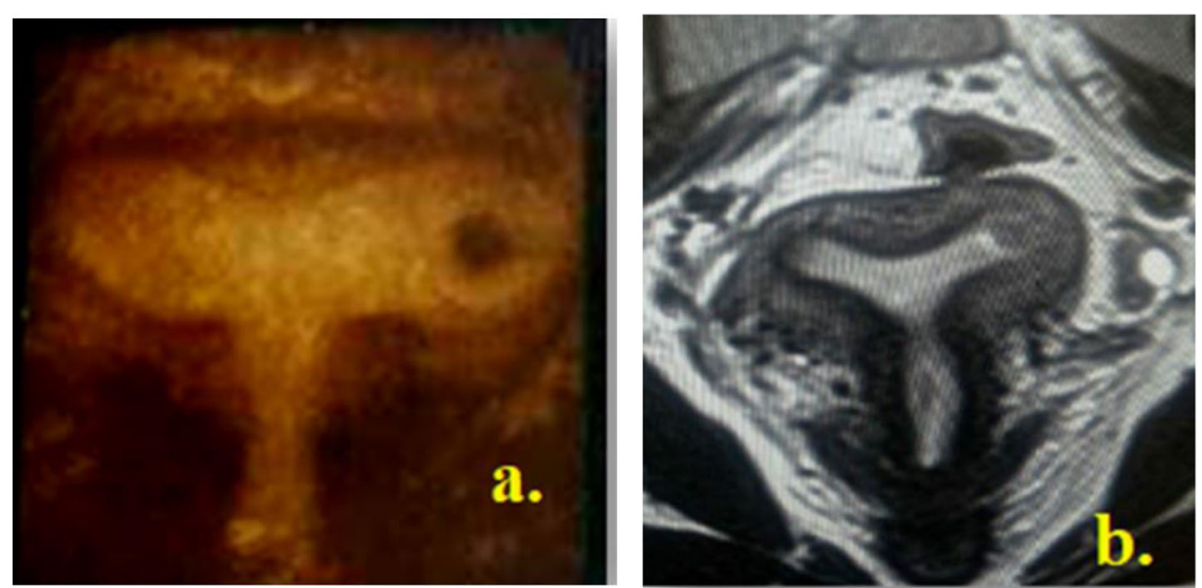

Fig. 4 A 28-year-old married female patient, complaining of abortion and 2-year infertility. Dysmorphic infantile uterus (class U1) by 3DTVS showed abnormal shape of the uterine cavity (not triangular) with uterine body to cervix ratio being 1:1, with mild internal indentation $<50 \%$ of uterine wall thickness (Fig. 1a). MR coronal T2 showing the same findings as 3DTVS (Fig. 1b)

findings were analyzed using the ESHRE-ESGE consensus classification as shown in Table 1 and Fig. 3.

\section{Statistical analysis}

- Scale data were presented as mean and standard deviation. Categorical data were presented as number (frequency) and percent.

- The agreement between both three-dimensional transvaginal ultrasound and MRI was presented as crosstab and kappa index of agreement. All significant $P$ values were less than 0.05 .

- The accuracy was calculated in the form of sensitivity, specificity, negative predicted value, and positive predicted value.

\section{Results}

According to the MRI findings, 2/30 (6.7\%) patients were categorized as class $U 0,4 / 30$ (13.3\%) cases were class $U 1$, $17 / 30(56.7 \%)$ patients were considered as class $U 2,2 /$ $30(6.7 \%)$ patients were class $U 3,3 / 30(10 \%)$ were class $U 4$, and $2 / 30(6.7 \%)$ cases were considered as class U5.

The following were according to the 3DTVS findings:

Class U1 (dysmorphic uterus) included five cases: four true cases $(4 / 5,80 \%)$ were (infantile) (Fig. 4). They showed internal indentation $<50 \%$ of the wall thickness, body to cervix ratio $=1: 1$, and no external cleft. One false case $(1 / 5,20 \%)$ was diagnosed as dysmorphic uterus class U1 while by MRI, it was classified as U0 associated with adenomyosis (Fig. 5). The diagnostic indices of 3DTVS were sensitivity $=100 \%$, specificity $=96.1 \%$, $\mathrm{PPV}=100 \%, \mathrm{NPV}=100 \%$, and $\mathrm{kappa}=0.970$.
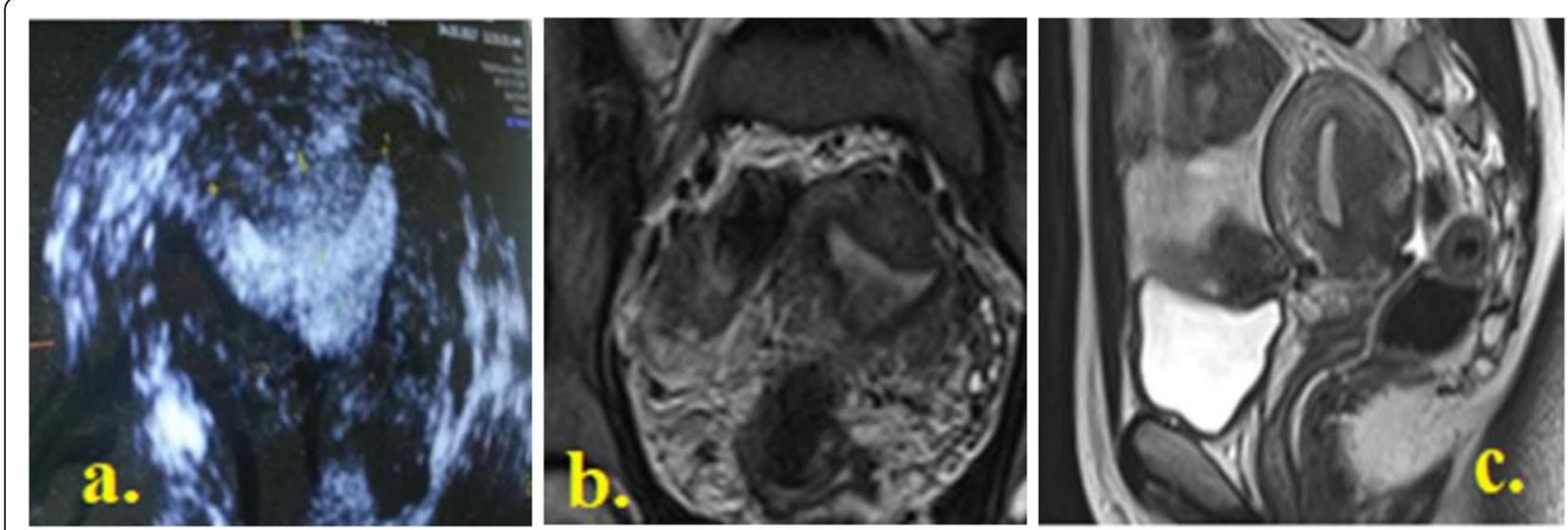

Fig. 5 A 28-year-old married female patient complaining of primary infertility. a Dysmorphic uterus (class U1) by 3DTVS showing fundal internal indentation $<50 \%$ of uterine wall thickness. b MRI coronal T2 showing fundal low signal intensity irregular areas indenting endometrial cavity. $\mathbf{c}$ Sagittal T2WI showing thick junctional zone exceeding $12 \mathrm{~mm}$ (uterine adenomyosis), class U0 according to MRI findings 

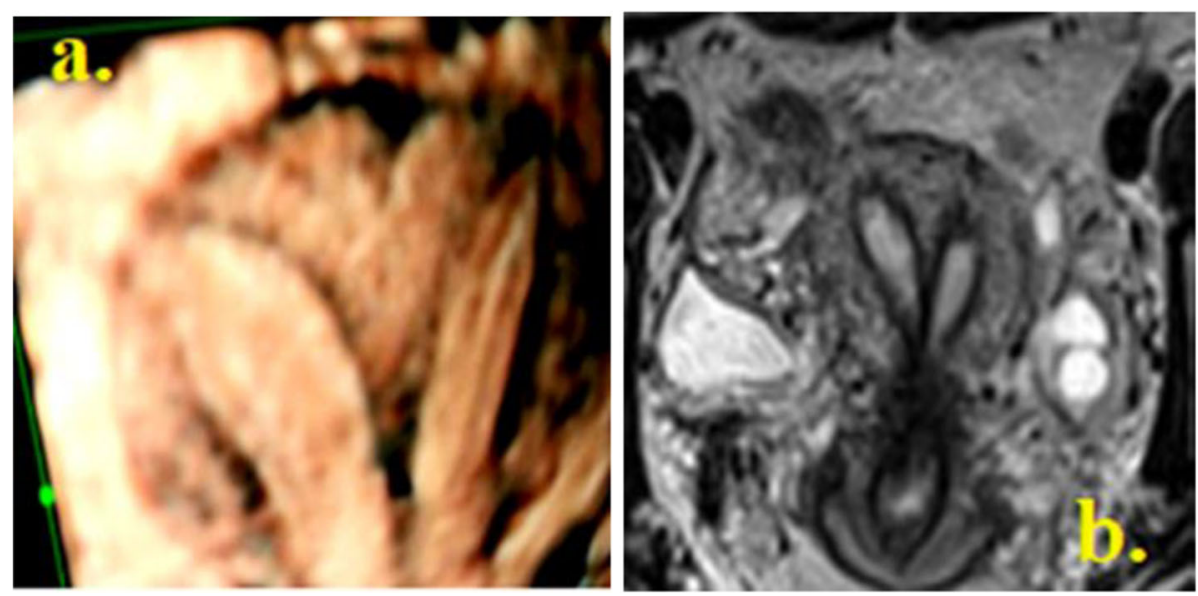

Fig. 6 A 21-year-old married female patient, complaining of primary infertility. a Partial septate uterus (class U2A) by 3DTVS showing straight fundal outline and the septum seen dividing uterine cavity into two equal uterine cavities. b MRI coronal T2WI showing the same findings as 3DTVS

Class $U 2$ included 16 cases: 15/16 (93.7\%) were true septate (Fig. 6) in which the internal indentation was $>50 \%$ of the wall thickness, with no external cleft. Only one false case $(1 / 16,6.2 \%)$ was diagnosed as subseptate by 3DTVS while by MRI, it was diagnosed as fibroid/adenomyosis uterus (class U0) (Fig. 7). The diagnostic indices of 3DTVS were sensitivity $=88.2 \%$, specificity $=92.3 \%, \mathrm{PPV}=93.8 \%$, $\mathrm{NPV}=85.7 \%$, and kappa $=0.936$.

Class $U 3$ included 4 cases: 2/4 (50\%) were true bicorporeal (Fig. 8) and 2/4 (50\%) were wrongly diagnosed by $3 \mathrm{D}$ TVS as bicorporeal and diagnosed by MRI as septate (class U2) (Figs. 9 and 10). The diagnostic indices of 3DTVS were sensitivity $=100 \%$, specificity $=92.8 \%$, $\mathrm{PPV}=50 \%, \mathrm{NPV}=100 \%$, and $\mathrm{kappa}=0.940$.

Class U4 included 3 cases: $3 / 3$ (100\%) were true unicornuate (Fig. 11). The diagnostic indices of 3DTVS were sensitivity $=100 \%$, specificity $=100 \%$, PPV $=100 \%$, $\mathrm{NPV}=100 \%$, and kappa $=1.000$.
Class U5 included 2 cases: 2/2 (100\%) were true hypoplastic. The diagnostic indices of 3DTVS were sensitivity $=100 \%$, specificity $=100 \%, \mathrm{PPV}=100 \%$, $\mathrm{NPV}=100 \%$, and kappa $=1.000$.

Concomitant other genitourinary anomalies were found in $7 / 30(23.3 \%)$ cases, the reported anomalies in 4/30(13.3\%) cases were absent kidney, 2/30(6.6\%) cases were malrotated kidney/anterior sacral meningocele, and $1 / 30(3.3 \%)$ case was vaginal cyst (Table 3 ).

The diagnostic accuracy and agreement of 3DTVS compared to MRI were illustrated in (Tables 4 and 5). There was a significant strong agreement between the diagnosis by 3D transvaginal ultrasound and MRI examination.

\section{Discussion}

Uterine anomalies are different groups of malformations with a broad spectrum of presentations [11]. Mullerian
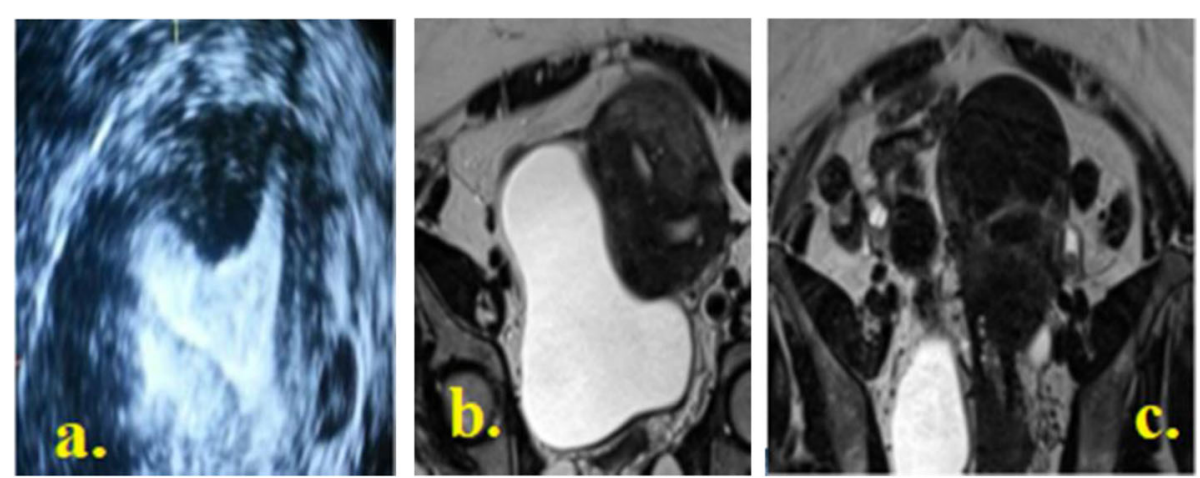

Fig. 7 A 40-year-old married female patient complaining of recurrent abortions. a Partial septate (class U2A) by 3DTVS showing fundal indentation $>50 \%$ of uterine wall thickness. b MRI coronal T2 showing areas of low signal causing fundal indentation. c Multiple focal myometrial lesions, fibroids. Class U0 according to MRI findings 

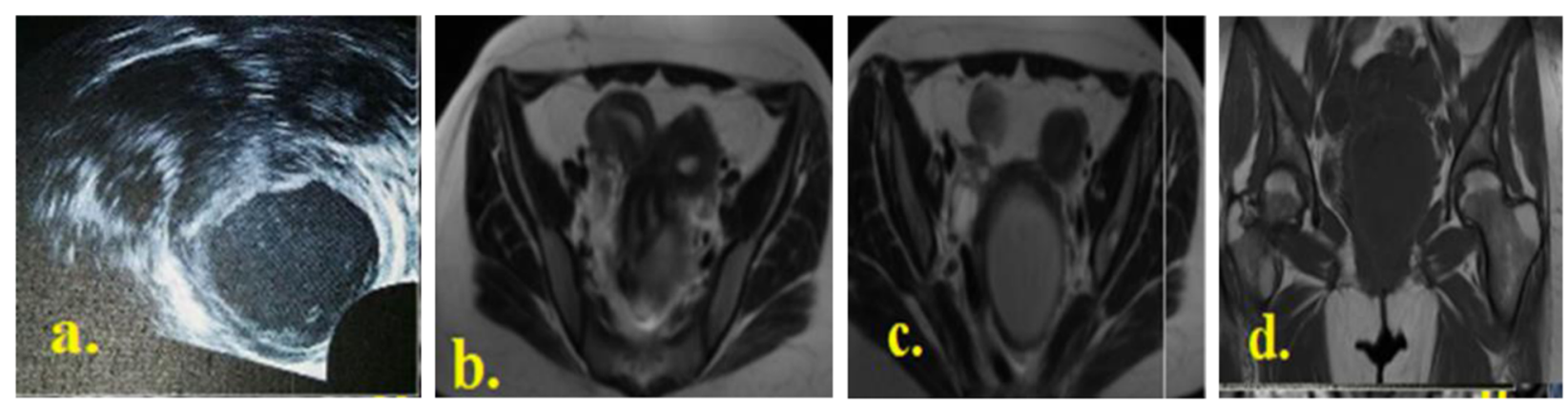

Fig. 8 A 23-year-old married female patient. a 3D TVS showing complete bicorporeal with two cervices and two vaginas (class U3b). b MRI coronal oblique T2 showing two uterine bodies and two cervices. c Coronal T2 oblique showed left vaginal lesion high signal in T2 and low signal in $\mathrm{T} 1$ (d)
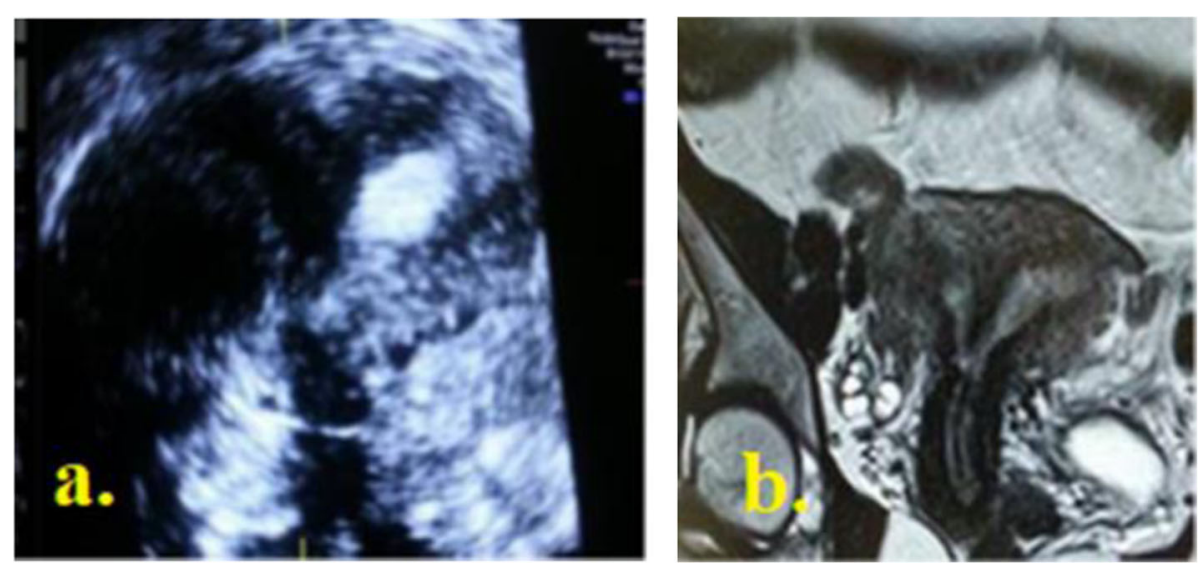

Fig. 9 A 28-year-old married female patient, complaining of infertility. a Bicorporeal septate uterus (class U3c) diagnosed by 3DTVS. It showed an external indentation at the fundal midline exceeding 50\% of the uterine wall thickness and an internal indentation width exceeded 50\% the uterine wall thickness. b MRI coronal oblique T2 showed straight fundal outline and complete septum. So, it was diagnosed by MRI as class U2b or complete septate uterus
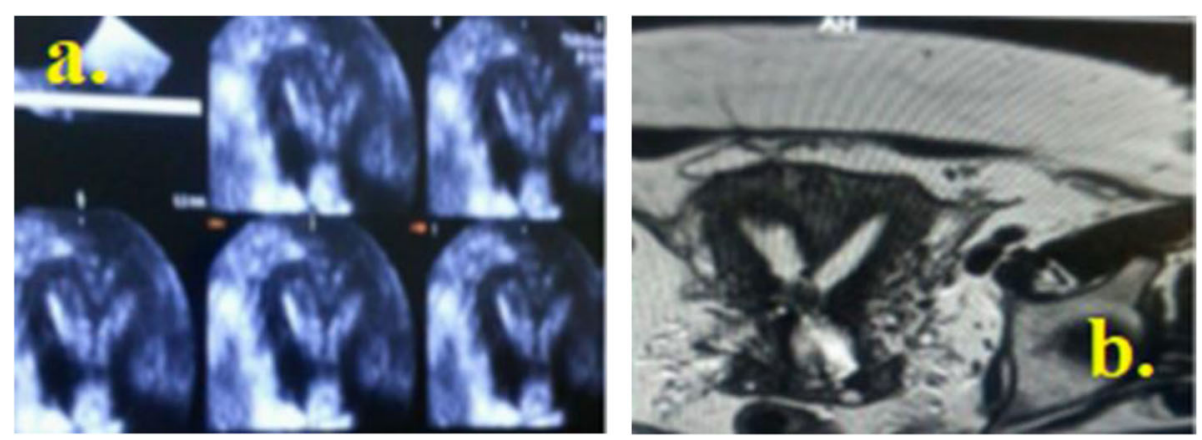

Fig. 10 A 40-year-old married female patient complaining of recurrent abortion. a Partial bicorporeal uterus (class U3a) diagnosed by 3DTVS showing external fundal indentation partially dividing cavity. b MRI coronal oblique T2 revealed straight fundal outline with septum partial dividing uterine cavity, diagnosed as partial septate uterus (class U2a) 

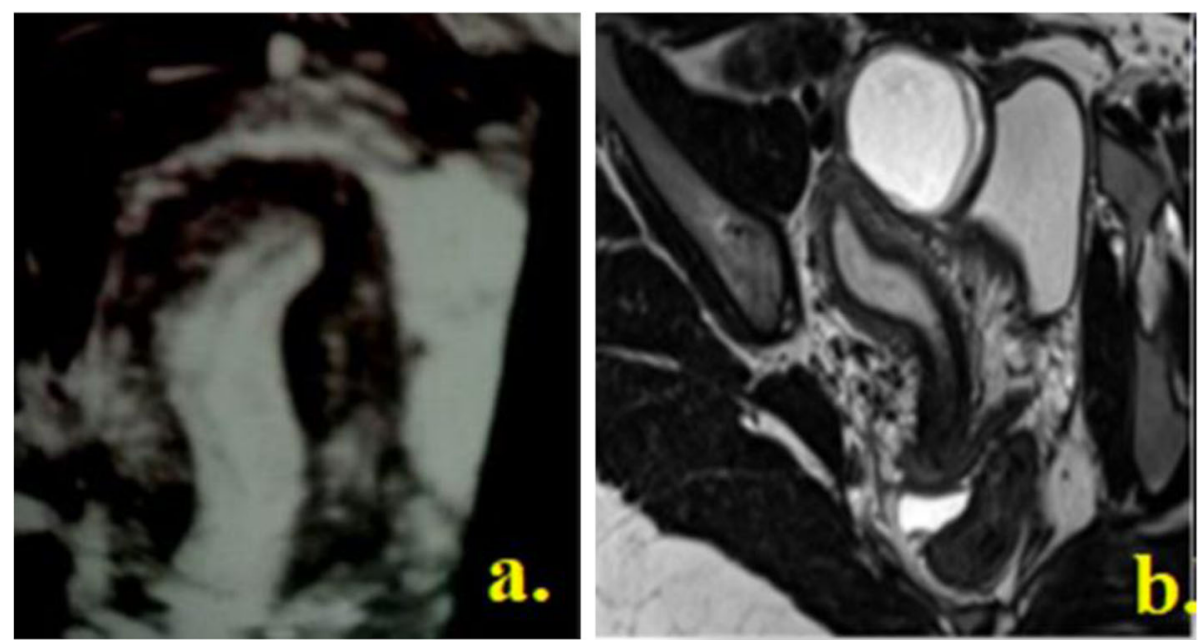

Fig. 11 An 18-year-old married female patient, complaining of infertility. a Unicoruate uterus, no functional rudimentary horn (class U4a). By 3D TV, it showed banana-shaped uterine cavity. b MRI coronal T2 showing banana-shaped uterine cavity and small functional ovarian cyst, with no rudimentary cavity

anomalies are initially suspected by 2DUS and/or with HSG done for infertility workup [8].

MRI is the most accurate imaging study for uterine anomalies; it reached a sensitivity and specificity of $92 \%$ and $100 \%$, respectively, compared to the results of combined hysteroscopy and laparoscopy [12].

In this study, we compared the efficiency of 3DTVS in diagnosing uterine anomalies to the MRI study, considering MRI as the standard reference. We used the ESHRE-ESGE consensus classification which provides objective parameters to classify uterine anomalies. This classification allows an accurate distinction between the different types of uterine anomalies with 3DTVS and MRI. This agrees with the study done by Graupera et al. [13] who reported that the ESHRE-ESGE classification provides objective parameters for diagnosing Mullerian duct anomalies (MDA).

The ESHRE-ESGE classification is more valuable than the ASRM classification. It shows uterine malformation main classes and subclasses. Cervical and vaginal anomalies are included as separate subclasses. So, ESHREESGE classification is more helpful in the diagnosis of complex anomalies of the female genital system [5].

Table 3 The associated anomalies with the Mullerian duct abnormalities in the study group

\begin{tabular}{lll}
\hline Associated anomalies & Number & Percent \\
\hline No other anomalies & 23 & 73.3 \\
Absent kidney & 4 & 13.3 \\
Malrotated kidney and anterior sacral meningocele & 1 & 3.3 \\
Malrotated kidney only & 1 & 3.3 \\
Vaginal cyst (Gartener duct cyst) & 1 & 3.3 \\
Total & 30 & 100 \\
\hline
\end{tabular}

We agreed with Robins et al. [14] who reported that septate uterus is the commonest uterine anomalies. In the present study, we found that septate uterus represented 17/30 (56.7\%) of our study population.

Septate uterus shows different morphological changes in both classifications. The ratio of internal fundal indentation to myometrial thickness was significantly lower in the ESHRE-ESGE classification than in the ASRM classification. Diagnosis of septate uterus by ESHRE-ESGE classification resembles the arcuate or normal uterus in the ASRM system [5]. The most important point in these classifications is to limit the overdiagnosis and improper treatment in cases of uterine anomalies. ESHRE-ESGE classification can guide the gynecologist to do the appropriate surgical treatment [10].

The limited positive predictive value of 3DTVS in our study was met in class U3 where four cases were included: 2/4 (50\%) were true bicorporeal and 2/4 (50\%) were wrongly diagnosed by 3DTVS as bicorporeal and diagnosed by MRI as septate (class U2), sensitivity $=100 \%$, specificity $=92.8 \%$, PPV $=50 \%$, and $\mathrm{NPV}=100 \%$. We attributed this to the limited tissue

Table 4 Accuracy of 3DTVS compared with MRI regarding diagnosis of Mullerian duct abnormalities of the present study

\begin{tabular}{llllll}
\hline Anomaly & Sensitivity & Specificity & PPV & NPV & Kappa \\
\hline Dysmorphic & $4 / 4(100)$ & $\begin{array}{l}25 / 26 \\
(96.1)\end{array}$ & $4 / 5(80)$ & $26 / 26(100)$ & 0.970 \\
& & $12 / 13$ & $15 / 16$ & $12 / 14$ & 0.936 \\
Septate & $15 / 17$ & $(92.3)$ & $(93.8)$ & $(85.7)$ & \\
& $(88.2)$ & $26 / 28$ & $2 / 4(50)$ & $26 / 26(100)$ & 0.940 \\
Bicorporal & $2 / 2(100)$ & $(92.8)$ & & & \\
& & $27 / 27(100)$ & $3 / 3(100)$ & $27 / 27(100)$ & 1.000 \\
Unicornuate & $3 / 3(100)$ & $28 / 28(100)$ & $2 / 2(100)$ & $28 / 28(100)$ & 1.000 \\
Aplastic & $2 / 2(100)$ & $28 / 2$ & & &
\end{tabular}


Table 5 Agreement between MRI and 3DTVS regarding diagnosis of Mullerian duct abnormalities of the current study

\begin{tabular}{|c|c|c|c|c|c|c|c|}
\hline $\begin{array}{c}3 \mathrm{D} \\
\text { ultrasound }\end{array}$ & $\begin{array}{l}\text { (U0) } \\
\text { Normal } \\
\text { uterus } \\
\text { No }(\%)\end{array}$ & $\begin{array}{c}(\mathrm{U} 1) \\
\text { Dysmorphic } \\
\text { No }(\%)\end{array}$ & $\begin{array}{r}(\mathrm{U} 2) \\
\text { Septate } \\
\text { No }(\%)\end{array}$ & $\begin{array}{l}\text { (U3) } \\
\text { Bicorporeal } \\
\text { No (\%) }\end{array}$ & $\begin{array}{l}\text { (U4) } \\
\text { Unicornuate } \\
\pm \text { rud. Cavity } \\
\text { No }(\%)\end{array}$ & $\begin{array}{r}\text { (U5) } \\
\text { Aplastic } \\
\text { /hypo- } \\
\text { plastic } \\
\text { No (\%) }\end{array}$ & $\begin{array}{l}\text { Total } \\
\text { No } \\
(\%)\end{array}$ \\
\hline $\begin{array}{r}\text { (U1) } \\
\text { Dysmorphic }\end{array}$ & $1(50)$ & $4(100)$ & $0(0)$ & $0(0)$ & $0(0)$ & $0(0)$ & $5(16.7)$ \\
\hline (U2) Septate & $1(50)$ & $0(0)$ & $15(88.2)$ & $0(0)$ & $0(0)$ & $0(0)$ & $16(53.3)$ \\
\hline $\begin{array}{l}\text { (U3) } \\
\text { Bicorporeal }\end{array}$ & $0(0)$ & $0(0)$ & $2(11.8)$ & $2(100)$ & $0(0)$ & $0(0)$ & $4(13.3)$ \\
\hline $\begin{array}{l}\text { (U4) } \\
\text { Unicornuate }\end{array}$ & $0(0)$ & $0(0)$ & $0(0)$ & $0(0)$ & $3(100)$ & $0(0)$ & $3(10)$ \\
\hline $\begin{array}{l}\text { (U5) } \\
\text { Aplastic } \\
\text { /hypoplastic }\end{array}$ & $0(0)$ & $0(0)$ & $0(0)$ & $0(0)$ & $0(0)$ & $2(100)$ & $2(6.7)$ \\
\hline Total & $2(100)$ & $4(100)$ & $17(100)$ & $2(100)$ & $3(100)$ & $2(100)$ & $30(100)$ \\
\hline
\end{tabular}

The shaded data represent disaggreement in the diagnosis between MRI and 3DTVS

resolution of US compared to MRI, and ultrasound is operator dependent. If the midcoronal plane is not ideal, this will give the wrong diagnosis. The problem of misdiagnosing the two cases of septate uterus by 3DUS in our study might be due to improper location of the line of the US beam during 3D reformatting which was at the level of the septum and not at the fundal level. So, it was better to move the line a little bit higher to assess the external contour of the uterus.

We found that $7 / 30(23.3 \%)$ cases had associated renal and other anomalies; this coincides with $\mathrm{Li}$ et al. [15] who reported that concomitant renal anomalies are found in 29\% of Mullerian duct anomalies cases.

In this study, the overall agreement between 3DTVS and MRI was $86.7 \%$ and the agreement coefficient (kappa) was 0.743 ; this coincided with the work of Bermejo et al. [7] who reported good agreement between 3D transvaginal US and MRI in diagnosing Mullerian duct anomalies, with a kappa index of 0.880 .

The limitations in our study were sampling bias, since we did 3DTVS only to patients with suspected uterine anomalies and some uterine anomalies that had a limited number in our study.

\section{Conclusion}

3DTVS proved to be highly accurate in the diagnosis of uterine anomalies and showed strong agreement with MRI, as both can provide valuable information about both the internal details and external contour of the uterus.

\section{Abbreviations}

3DTVS: Three-dimensional transvaginal sonographyASRMThe American Society for Reproductive MedicineESHRE-ESGEThe European Society of Human Reproduction and Embryology-European Society for Gynaecological EndoscopyMDAMullerian duct anomaliesHSGHysterosalpingography

\section{Acknowledgements}

Not applicable.

\section{Authors' contributions}

SA carried out the statistical analysis, data collection, image analysis, and drafting and editing of the paper. NA shared in the image analysis and interpretation. AS shared in the design and drafting of the manuscript. MS participated in the data collection and clinical assessment. All contributing authors have read and approved the final manuscript.

\section{Funding}

No funding resources.

\section{Availability of data and materials}

All data are available at the corresponding author who has the authority to respond if there is any query.

\section{Ethics approval and consent to participate}

The study was approved by the ethical committee of Faculty of Medicine Beni-Suef University (FWA00015575). The data were collected after obtaining informed written consent of all cases.

\section{Consent for publication}

All patients included in this research gave written informed consent to publish the data contained in this study. 


\section{Competing interests}

The authors declare that they have no competing interests.

\section{Author details}

${ }^{1}$ Radiology Department, Faculty of Medicine, Beni-Suef University, Beni Suef, Egypt. ${ }^{2}$ Obstetrics and Gynecology Department, Faculty of Medicine,

Beni-Suef University, Beni Suef, Egypt.

Received: 22 January 2020 Accepted: 26 February 2020

Published online: 17 March 2020

\section{References}

1. Olpin JD, Heilbrun M (2009) Imaging of Mullerian duct anomalies. Clin ObestetGynecol 52:40-56

2. Saravelos SH, Cocksedge KA, Li TC (2008) Prevalence and diagnosis of congenital uterine anomalies in women with reproductive failure: a critical appraisal. Hum Reprod Update 14:415-429

3. Acie'n P, Acie'n Ml (2011). The history of female genital tract malformation classifications and proposal of an updated system. Hum Reprod Update; 17: 693-705.

4. Grimbizis GF, Gordts S, Di Spiezio Sardo A, Brucker S, De Angelis C, Gergolet M, Li TC, Tanos V, Brölmann H, Gianaroli L et al (2013) The ESHRE/ ESGE consensus on the classification of female genital tract congenital anomalies. Hum Reprod 28:2032-2044

5. Ludwin A, Ludwin I (2015) Comparison of the ESHRE-ESGE and ASRM classifications of Mullerian duct anomalies in everyday practice. Human Reprod 30(3):569-580

6. Grimbizis G.F, Campo R, Tarlatzis B.C et al. (eds.) (2015), Female genital tract congenital malformations: 99 classification, diagnosis and management, Springer-Verlag London.

7. Bermejo C, Mart P, Cantarero R, Diaz D, Pedregosa JP, Barro' NE, Labrador E, LR LL (2010) Three-dimensional ultrasound in the diagnosis of Müllerian duct anomalies and concordance with magnetic resonance imaging. Ultrasound ObstetGynecol 35:593-601

8. Khaled AA, Mohammed MH, Dina GE (2014) Septate or bicornuate uterus: accuaracy of three-dimensional transvaginal ultrasounography and pelvic magnetic resonance imaging. Egypt J Radiol Nuclear Med 45:987-995

9. Deutch TD, Abuhamad AZ (2008) The role of 3-dimensional ultrasonography and magnetic resonance imaging in the diagnosis of Müllerian duct anomalies. J Ultrasound Med 27:413-423

10. Ludwin A, Ludwin I, Pityn'ski K, Banas T, Jach R (2014) Role of morphologic characteristics of the uterine septum in the prediction and prevention of abnormal healing outcomes after hysteroscopic metroplasty. Hum Reprod 29:1420-1431

11. El Huseiny AM, Ahmad RA, Sadek SM, Gouhar GK, Dawood HA (2014) Role of three-dimensional ultrasound in the diagnosis of double uterine cavity anomalies and concordance with laparoscopic and hysteroscopic diagnosis. Egypt J Radiol Nuclear Med 45:555-560

12. Bello AB, Fernandez MA, Gálvez CG (2010).Uterine malformations assessment: MRI vs laparoscopyhysteroscopy .ECR 2010

13. Graupera B, Pascual MA, Hereter L, Browne JL, Úbeda B, Rodríguez I, Pedrero C (2015) Accuracy of three-dimensional ultrasound compared with magnetic resonance imaging in diagnosis of Müllerian duct anomalies using ESHRE-ESGE consensus on the classification of congenital anomalies of the female genital tract. Ultrasound Obstet Gynecol 46:616-622

14. Robbins JB, Broadwell C, Chow LC, Parry JP, Sadowski EA (2015) Müllerian duct anomalies: embryological development, classification, and MRI assessment. J MagnReson Imaging 41:1-12

15. Li S, Qayyum A, Coakley FV, Hricak H (2000) Association of renal agenesis and mullerian duct anomalies. J Comput Assist Tomogr 24:829-834

\section{Publisher's Note}

Springer Nature remains neutral with regard to jurisdictional claims in published maps and institutional affiliations.

\section{Submit your manuscript to a SpringerOpen ${ }^{\circ}$ journal and benefit from:}

- Convenient online submission

- Rigorous peer review

- Open access: articles freely available online

- High visibility within the field

- Retaining the copyright to your article

Submit your next manuscript at $\boldsymbol{\nabla}$ springeropen.com 